\title{
EVALUATION OF SAFETY WHEN A SEISMIC ISOLATED BUILDING COLLIDES WITH RETAINING WALLS CONSIDERING DIFFERENT NUMBERS OF FLOORS
}

\author{
CARLOS CUADRA \& KENTA KIKUCHI \\ Faculty of System Science and Technology, Akita Prefectural University, Japan
}

\begin{abstract}
Large dynamic responses of long-period buildings were observed during strong earthquakes, especially when these input motions are of large amplitude or long duration and low frequency content. A base isolated building is basically a structure of long period and therefore large displacement response could be observed during mentioned earthquakes. This large displacement of the isolation layer could cause the collision of the isolated structure against the surrounding retaining walls. This research uses 5 -storey and 10-storey three-dimensional building models to investigate the safety of base isolated structures in the event of impact against retaining walls. The analytical models consider gap link elements to study the collision against the retaining wall. As input acceleration, a record of the Kobe earthquake was used, scaling this record by 1, 1.7, 1.8 and 2. For both models, maximum acceleration in upper structure increases in case of collision. Since this acceleration could cause furniture to tip over, a safety analysis is performed based on predominant frequency of vibration and maximum acceleration observed on each floor. In case of no collisions, there is less than a 30\% probability that the furniture will tip over in all cases of seismic waves. When a collision occurs, the acceleration at each floor increases significantly and the probability that the furniture will fall is $50 \%$ or more.
\end{abstract}

Keywords: rubber isolator, collision, seismic response analysis, finite element method, gap element.

\section{INTRODUCTION}

In Japan, located in an active seismic region, major earthquakes such as the Great East Japan earthquake (2011) and the Kumamoto earthquake (2016) have occurred, and many people lost their homes due to the collapse of buildings. Seismic isolation is a technology that protects building structures from shaking due to earthquake motions [1]. According to the data collection of the Japan Society of Seismic Isolation, the stock of isolated buildings reaches approximately 5,000 structures, and the number of isolated housing structures (residential houses) reaches approximately 4,700 units [2].

During the 2011 East Japan earthquake, low frequency (or long period) content acceleration records were observed in many points of Japan [3] and these signals induced large displacement responses or long duration responses of isolated buildings, since these structures have a long period of vibration and therefore resonance phenomenon could occur. On the other hand, in 2016, during the Kumamoto earthquake (near field earthquake) high amplitude signals were observed and therefore large amplitude response of the isolated buildings was also observed (displacement of the order of $40 \mathrm{~cm}$ ). Then, it is necessary to investigate the case of probable collision of an isolated structure against surrounding retaining walls [4], [5]. When the collision occurs, the input acceleration is amplified on the upper floors and the accelerations on each floor could cause damage to the structure itself or could cause the furniture to tip over, affecting the safety of the structure and its content. Fig. 1 shows, schematically, the effect of the impact of isolated building against the retaining walls. In addition to damage to building and overturning of furniture, the collision could lead to crushing of retaining walls and buckling of isolation devices [6], [7]. 


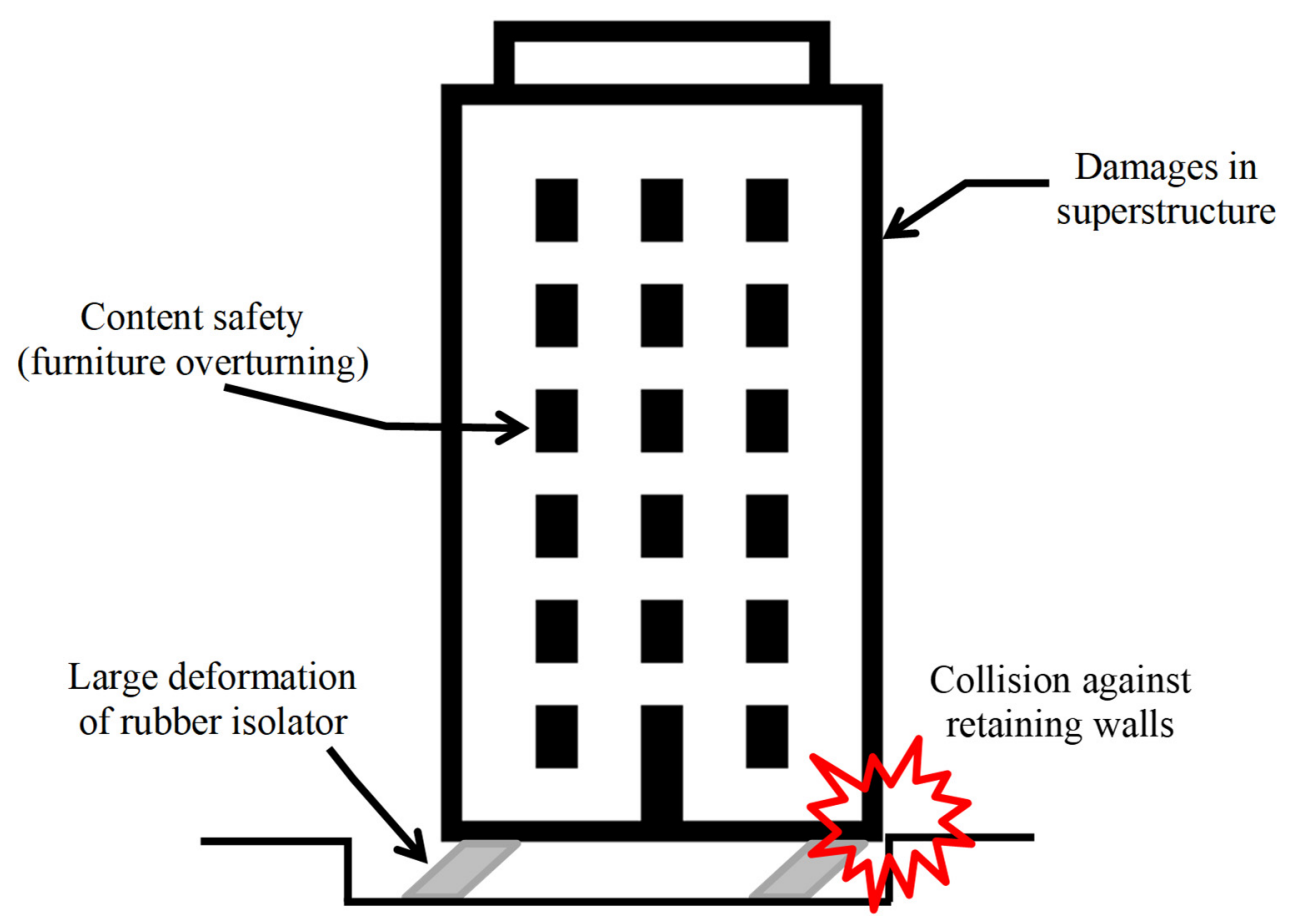

Figure 1: Collision of a seismic isolated building against retaining walls.

In this research, two building models are chosen to investigate the effect of the collision of isolated structures. The 5-storey building and the 10-storey building are modelled using structural analysis software called Etabs. Isolation devices are modelled using rubber isolator link element and the impact against retaining wall is modelled with a spring gap link element [8]. Kobe earthquake record (Japan Meteorological Agency (JMA), 1995) is used as the input motion. From this time-history response analysis, maximum accelerations on each floor are obtained and with the analysis of the predominant frequency a verification of the safety of the furniture is carried out [9].

\section{TARGET ISOLATED STRUCTURES AND FEM MODELS}

In the present analysis, a 5-storey mid-rise building and a 10 -storey tall building are considered to investigate the effect of the difference in the number of stories on the response and safety of these target buildings. In both cases the buildings correspond to reinforced concrete frame structures. If they are considered as non-isolated buildings, they have different periods of vibration. However, for isolated buildings, in both structures the isolated devices are designed in such a way that they have the same period of vibration.

The design criteria of target buildings consider that the period of vibration of the 5-storey structure should be less than $0.5 \mathrm{~s}$ and for 10-storey structure the period should be less than $1 \mathrm{~s}$. In both cases the period of vibration for isolated building must be between $3 \mathrm{~s}$ to $4 \mathrm{~s}$.

Currently, the design clearance is $60 \mathrm{~cm}$; however, for the first isolated buildings, the design considered a clearance of $40 \mathrm{~cm}$. Therefore, in this study, this clearance of $40 \mathrm{~cm}$ will be considered for the impact analysis. 


\subsection{Characteristics of 5-storey building}

Fig. 2 shows the characteristics of the 5-storey building such as the dimensions of the building and its properties of mass and clearance of the isolation floor.
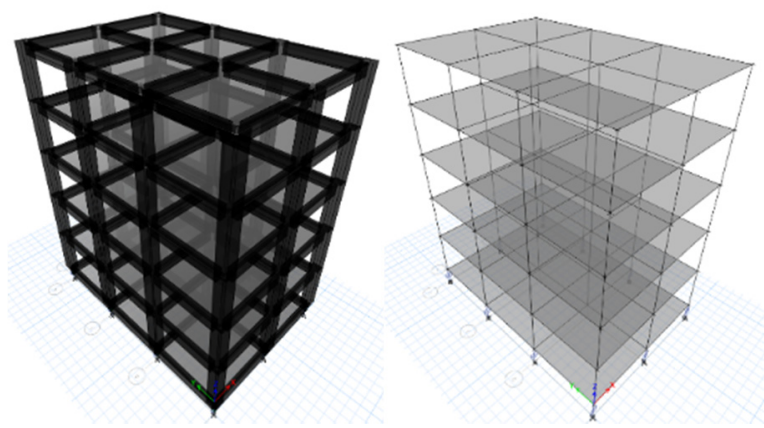

Height: $20 \mathrm{~m}$

Storey height: $4 \mathrm{~m}$

Plan dimension: $16 \mathrm{~m} \times 18 \mathrm{~m}$

Floor area: $1,300 \mathrm{~m}^{2}$

Structure: Reinforced concrete

Column cross section: $800 \times 800$

Beam cross section: 750 x 400

Floor slab: $350 \mathrm{~mm}$

Total weight: $1483 \mathrm{t}$

Clearance: $400 \mathrm{~mm}$

Figure 2: 5-storey building model.

\subsection{Characteristics of 10 -storey building}

Fig. 3 shows the characteristics of the 10-storey building such as the dimensions of the building and its properties of mass and clearance of the isolation floor.
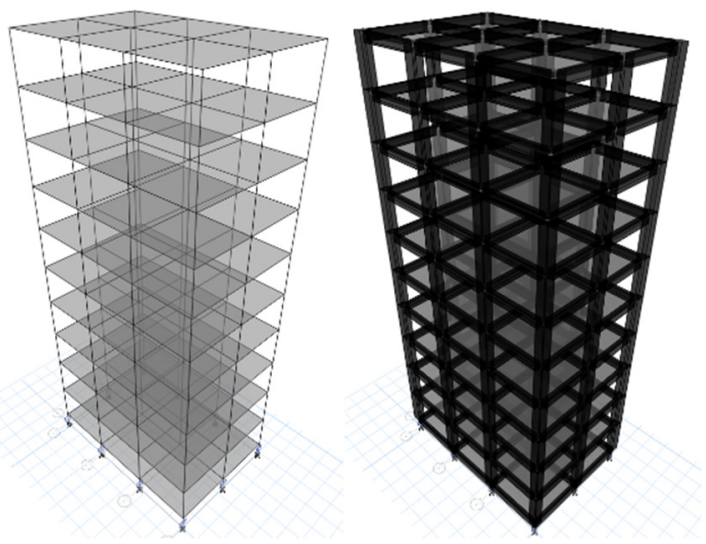

Height: $40 \mathrm{~m}$

Storey height: $4 \mathrm{~m}$

Plan dimension: $16 \mathrm{~m} \times 18 \mathrm{~m}$

Floor area: $2,400 \mathrm{~m}^{2}$

Structure: Reinforced concrete

Column cross section: $800 \times 800$

Beam cross section: $750 \times 400$

Floor slab: $350 \mathrm{~mm}$

Total weight: $2759 \mathrm{t}$

Clearance: $400 \mathrm{~mm}$

Figure 3: 10-storey building model.

\subsection{Base isolated models}

For base-isolated structures, the equivalent stiffness of the isolation layer is calculated considering that the target period of vibration is $3.5 \mathrm{~s}$. If the entire structure above the isolated layer is considered as a lumped mass $(m)$ and if the stiffness of the isolation devices is $K$, then the period of vibration of the isolated structure is given by the following equation: 


$$
T=2 \pi \sqrt{\frac{m}{K}}
$$

Then, considering $T=3.5 \mathrm{~s}$, the equivalent stiffness of the isolation layer is obtained from the following equation:

$$
K=\frac{4 \pi^{2}}{3.5^{2}} m
$$

If $K$ is the total stiffness of the isolated layer and considering that 10 devices are used, then the stiffens of a device (rubber isolator) is $k=K / 10$. The stiffnesses required for the isolation layer and the devices for each model are as follows:

$$
\begin{aligned}
& \text { 5-storey building: } K=4779 \mathrm{kN} / \mathrm{m}, k=478 \mathrm{kN} / \mathrm{m} \\
& \text { 10-storey building: } K=8891 \mathrm{kN} / \mathrm{m}, k=889 \mathrm{kN} / \mathrm{m}
\end{aligned}
$$

High damping rubber isolators are selected for the target buildings. The equivalent lateral stiffness of each isolator must be closer to the calculated stiffness $k$, however not greater than this value in order to obtain the estimated period. Table 1 shows the properties of the selected isolation devices for both target buildings.

Table 1: Properties of rubber isolators.

\begin{tabular}{|l|c|c|}
\hline \multirow{2}{*}{ Device property } & \multicolumn{2}{|c|}{ Target building } \\
\cline { 2 - 3 } & 5-storey building & 10-storey building \\
\hline Name or code & HN060X3R & HL065X4S \\
\hline Type & High damping rubber & High damping rubber \\
\hline Diameter & $600 \mathrm{~mm}$ & $650 \mathrm{~mm}$ \\
\hline Weight & $5 \mathrm{kN}$ & $6.3 \mathrm{kN}$ \\
\hline Initial stiffness & $3,060 \mathrm{kN} / \mathrm{m}$ & $4,730 \mathrm{kN} / \mathrm{m}$ \\
\hline Second stiffness & $306 \mathrm{kN} / \mathrm{m}$ & $473 \mathrm{kN} / \mathrm{m}$ \\
\hline Yield load & $23.7 \mathrm{kN}$ & $53.0 \mathrm{kN}$ \\
\hline Equivalent lateral stiffness & $424 \mathrm{kN} / \mathrm{m}$ & $799 \mathrm{kN} / \mathrm{m}$ \\
\hline Equivalent damping factor & 0.17 & 0.24 \\
\hline
\end{tabular}

A modal analysis was carried out for non-isolated and isolated buildings to obtain their predominant periods of vibration. Table 2 shows results of this modal analysis. For noisolated buildings, the target periods were shorter that $0.5 \mathrm{~s}$ for the 5 -storey building and shorter that $1 \mathrm{~s}$ for the 10 -storey building. The periods obtained are $0.44 \mathrm{~s}$ and $0.86 \mathrm{~s}$ for the 5 -storey building and the 10 -storey building respectively. For isolated buildings was assumed that the period of vibration must be between $3 \mathrm{~s}$ to $4 \mathrm{~s}$. The actual periods of vibration obtained for isolated buildings are $3.32 \mathrm{~s}$ and $3.30 \mathrm{~s}$ for the 5 -storey building and the 10storey building, respectively.

Table 2: Modal analysis results.

\begin{tabular}{|l|c|c|c|c|}
\hline \multirow{2}{*}{ Period of vibration } & \multicolumn{2}{|c|}{ 5-storey building } & \multicolumn{2}{c|}{ 10-storey building } \\
\cline { 2 - 5 } & Non-isolated & Isolated & Non-isolated & Isolated \\
\hline Target period & $\mathrm{T}<0.5 \mathrm{~s}$ & $3 \mathrm{~s}<\mathrm{T}<4 \mathrm{~s}$ & $\mathrm{~T}<1.0 \mathrm{~s}$ & $3 \mathrm{~s}<\mathrm{T}<4 \mathrm{~s}$ \\
\hline Analysis result & $0.44 \mathrm{~s}$ & $3.32 \mathrm{~s}$ & $0.86 \mathrm{~s}$ & $3.30 \mathrm{~s}$ \\
\hline
\end{tabular}




\section{SEISMIC RESPONSE ANALYSIS}

The target isolated buildings were subjected to a time-history analysis. As input motion, a record obtained during the Kobe earthquake (JMA, 1995) was used. Then the displacement responses and acceleration responses in the event of a collision with the retaining wall are studied.

\subsection{Input motion}

Fig. 4 shows the original input motion (kobe-1) and the amplified signal (kobe-1.7, kobe-1.8, kobe-2). The amplification factors of 1.7, 1.8 and 2 were chosen to produce the collision or to obtain a displacement larger than the clearance, which is $40 \mathrm{~cm}$ in this study.

The original Kobe signal with a maximum acceleration of $817 \mathrm{~cm} / \mathrm{s}^{2}$ does not cause collisions of isolated buildings. As a verification of the proper behaviour of the rubber insulators, the responses of these devices were obtained in the case of the original Kobe input movement as shown in Fig. 5. These responses are shown for the 5-storey building (5F) and the 10-storey building (10F).

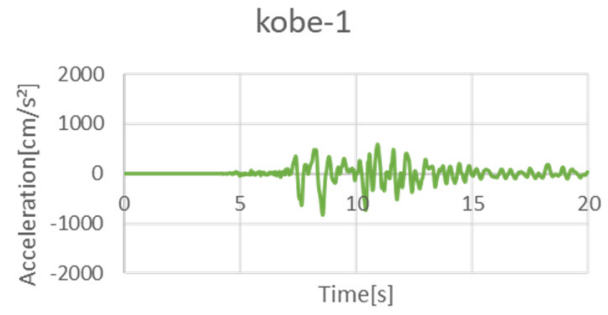

kobe-1.8

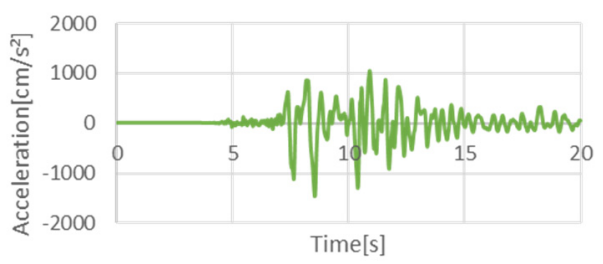

kobe-1.7

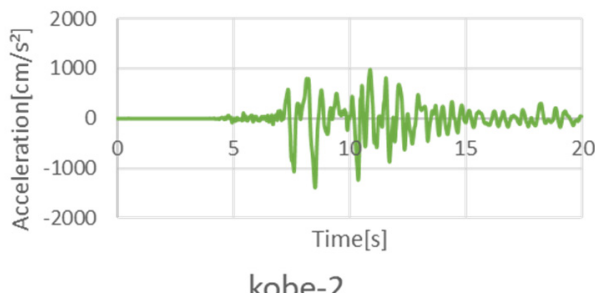

kobe-2

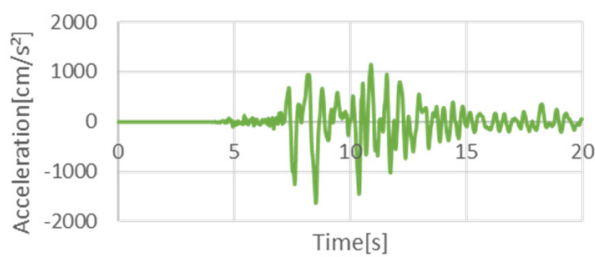

Figure 4: Input motion for time--history analysis.

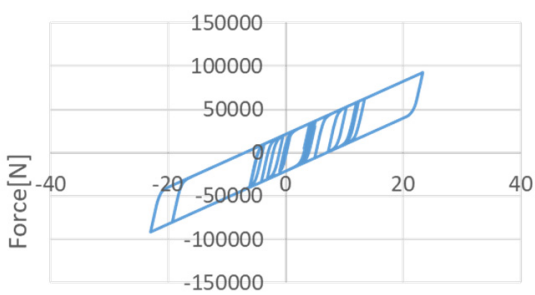

Displacement $[\mathrm{cm}] \quad-5 \mathrm{~F}$

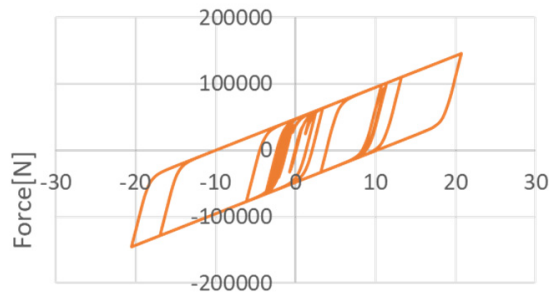

Displacement $[\mathrm{cm}] \quad-10 \mathrm{~F}$

Figure 5: Responses of rubber isolators for isolated buildings. 


\subsection{Response analysis}

Fig. 6 shows the displacement responses of the isolated 5-storey building during various levels of Kobe input motion. For the original Kobe record (kobe-1) the maximum displacement is $23.4 \mathrm{~cm}$, which is less than $40 \mathrm{~cm}$ of clearance. If the input signal is amplified by $1.7,1.8$ and 2, the maximum response is $43.8 \mathrm{~cm}, 48.9 \mathrm{~cm}$, and $62.6 \mathrm{~cm}$, respectively. In these cases, the maximum responses exceed the clearance of $40 \mathrm{~cm}$ and, therefore, it is assumed that the structure collides with the retaining walls.

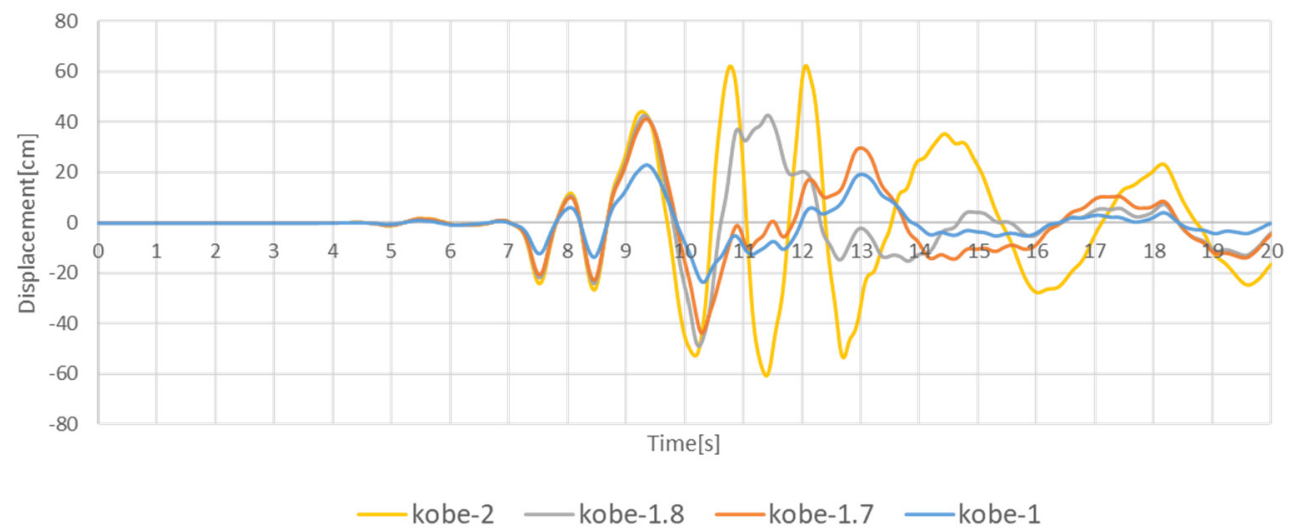

Figure 6: Displacement response for the isolated 5-storey building.

Fig. 7 shows the displacement responses of isolated 10-storey building when subjected to various level of Kobe input motion. For the original Kobe record (kobe-1) and amplification factor of 1.7, the maximum displacements are $20.8 \mathrm{~cm}$ and $39.1 \mathrm{~cm}$, respectively, which are less than $40 \mathrm{~cm}$ of clearance. When the input signal is amplified by 1.8 and 2; the maximum responses are $41.3 \mathrm{~cm}$, and $48.6 \mathrm{~cm}$ respectively. In these cases, the maximum responses exceed the clearance of $40 \mathrm{~cm}$ and, therefore, is assumed that the structure collides with the retaining walls.

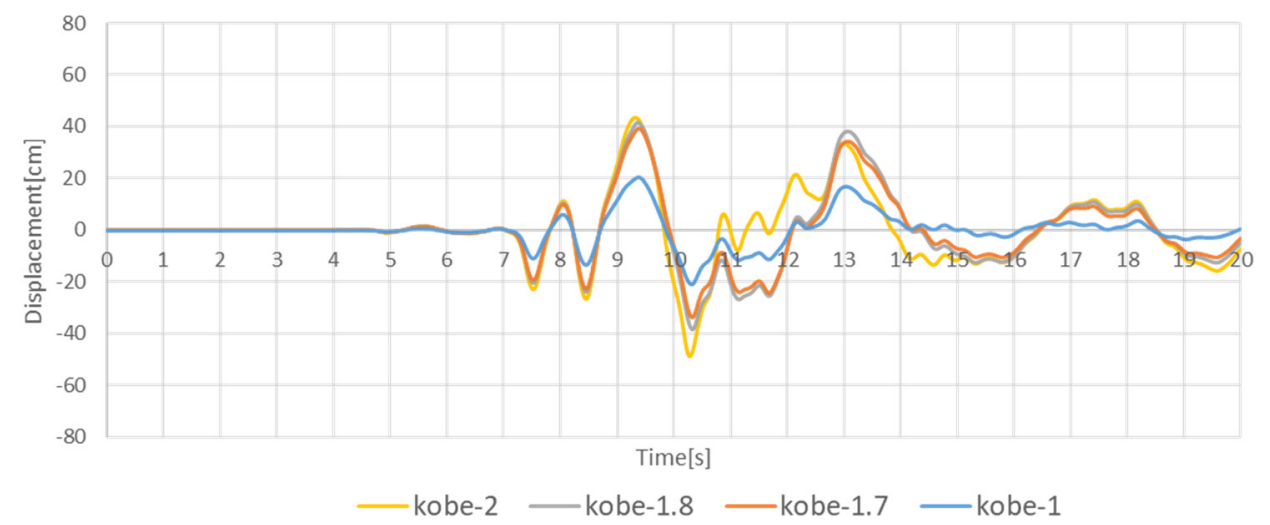

Figure 7: Displacement response for the isolated 10-storey building. 
Comparing the acceleration responses, it can be seen that when the displacement response exceeds $40 \mathrm{~cm}$ of clearance, the maximum acceleration increases significantly due to the collision with the retaining wall. However, since the maximum displacement differs for each building, the displacement crush of the retaining walls will affect the reaction force due to impact and the maximum acceleration will be different for each building and for each amplification factor. The reaction force in case of collision is modelled by a linear spring of high stiffness that reacts when the clearance is exceeded.

Fig. 8 shows the acceleration response of the 5 -storey building. For original Kobe earthquake (kobe-1) the maximum acceleration at the top of the building is $135 \mathrm{~cm} / \mathrm{s}^{2}$. Since the maximum input acceleration is $817 \mathrm{~cm} / \mathrm{s}^{2}$, in this case the isolation effect is confirmed by observing this decrease in acceleration. The acceleration amplification factor is less than 1 $(135 / 817=0.17)$. In the case of amplified input motions, the maximum accelerations are $1,283 \mathrm{~cm} / \mathrm{s}^{2}, 2,151 \mathrm{~cm} / \mathrm{s}^{2}$, and $3,594 \mathrm{~cm} / \mathrm{s}^{2}$ for amplification factors of $1.7,1.8$ and 2 respectively. For this 5 -storey building, it is clear that when the maximum displacement response exceeds clearance, a collision occurs and the acceleration is amplified.

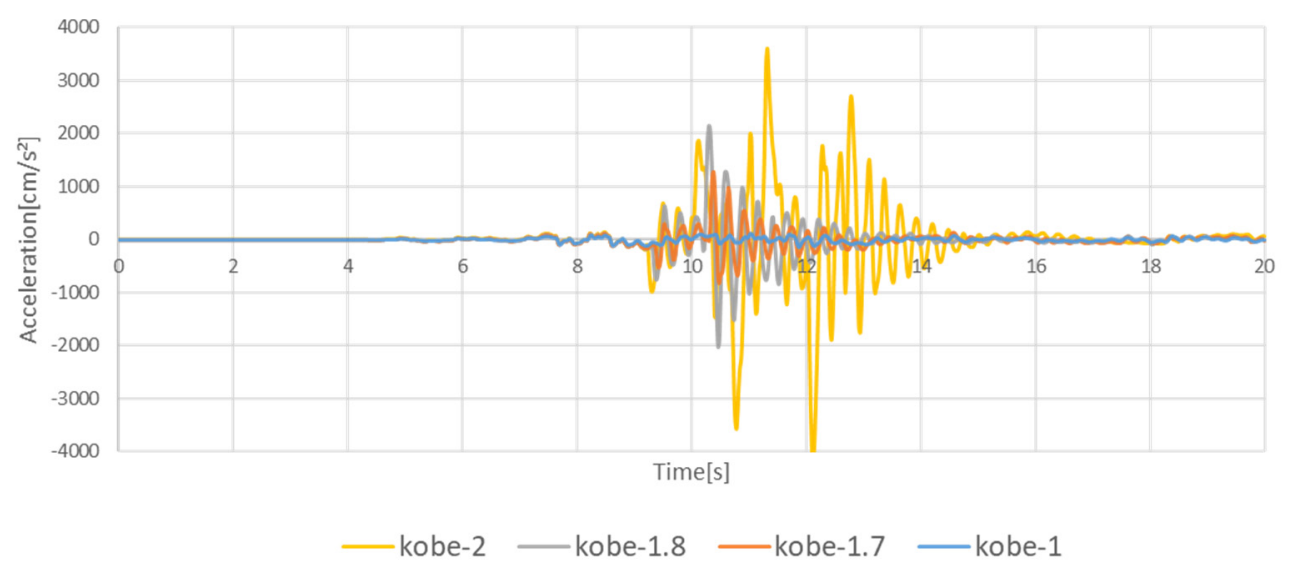

Figure 8: Acceleration response for the isolated 5-storey building.

Fig. 9 shows the acceleration response of the isolated 10-storey building. For the original Kobe earthquake (kobe-1), the maximum acceleration at the top of the building is $257 \mathrm{~cm} / \mathrm{s}^{2}$. In this case, the isolation effect is confirmed with the acceleration amplification factor less than $1(257 / 817=0.32)$. When the input is amplified by 1.7 , the maximum displacement is still less than the clearance and therefore there is no collision, and the isolation effect is still confirmed with a maximum acceleration of $326 \mathrm{~cm} / \mathrm{s}^{2}$. For 1.8 of amplification factor, the clearance is exceeded by a small amount and the maximum acceleration increases to $370 \mathrm{~cm} / \mathrm{s}^{2}$. Finally, for the amplification factor of 2, the maximum acceleration is $1514 \mathrm{~cm} / \mathrm{s}^{2}$.

Although the 5-storey isolated building and the 10-storey isolated building have almost the same predominant period of vibration, the corresponding maximum displacement and acceleration responses differ. It was expected that in the event of an impact from the same earthquake, the 10-storey building could produce a greater acceleration response due to greater mass. However, this larger mass causes smaller displacement responses and therefore the number of impacts or penetration against the retaining walls is also less. This results in a lower reaction force due to impact, also resulting in a lower acceleration response. 


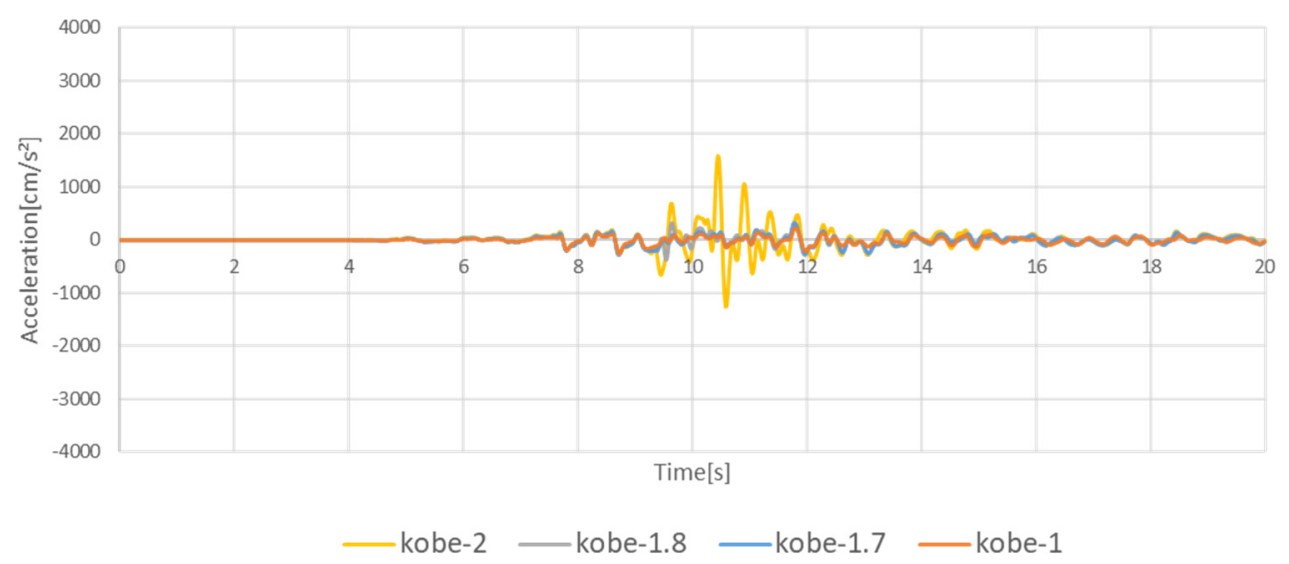

Figure 9: Acceleration response for the isolated 10-storey building.

\section{ANALYSIS OF BUILDING CONTENT SAFETY}

The safety of the building content is evaluated based on the failure flow and sliding of furniture proposed by Kaneko et al. [9]. An overturning limit acceleration and a slipping start acceleration are defined considering the predominant frequency of vibration of each floor. The predominant frequency of each floor is obtained from Fourier spectrum of signal obtained at the corresponding floor. The acceleration parameters also depend on the type of furniture, the dimensions, and the friction coefficient between the furniture and the floor slab. In this analysis, a representative piece of furniture (bookshelf) is selected. Dimensions of this piece of furniture is $200 \mathrm{~cm}$ high, $40 \mathrm{~cm}$ wide and 0.3 is assumed as the friction coefficient.

Fig. 10 shows the results of the furniture overturning probability analysis for the 5-storey building when is subjected to the original Kobe earthquake. In this case, the building does not collide against retaining walls and acceleration response of each floor is below the overturning limit. In other words, the contents of the building are safe.

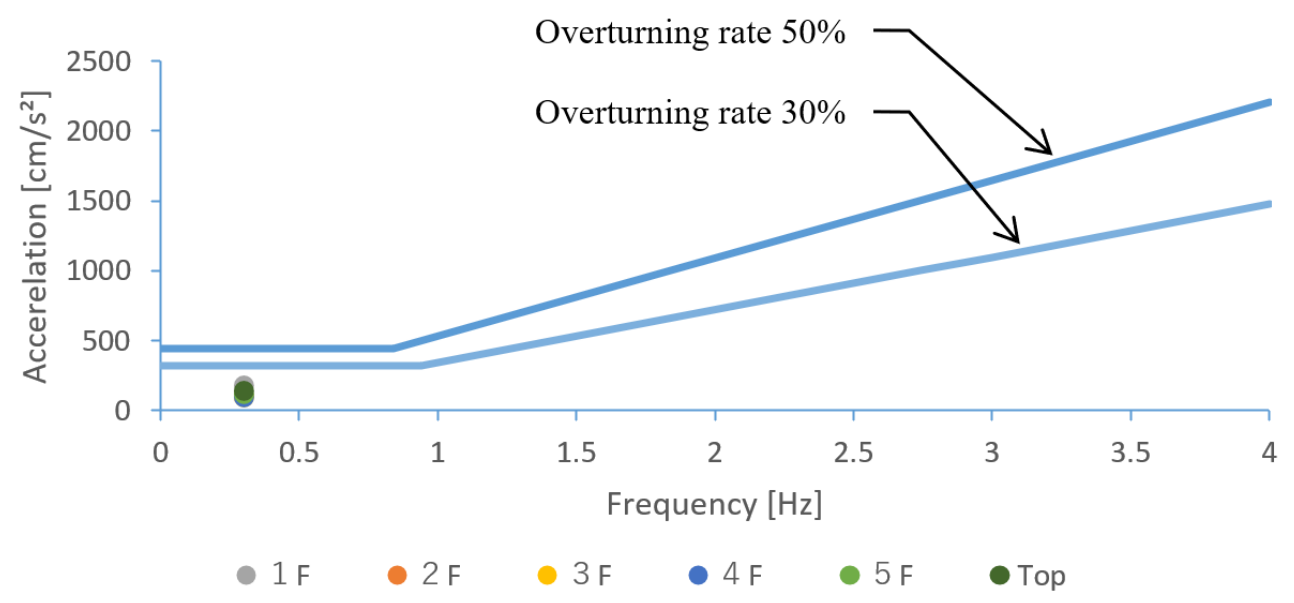

Figure 10: Acceleration and floor response for the isolated 5-storey building (no collision). 
Fig. 11 shows the results of the analysis of the probability of furniture overturning for a 10 -storey building when subjected to the original Kobe earthquake. In this case, the building also does not collide with the retaining walls and the acceleration response of each floor is below the overturning limit. In this case also the contents of the building are safe.

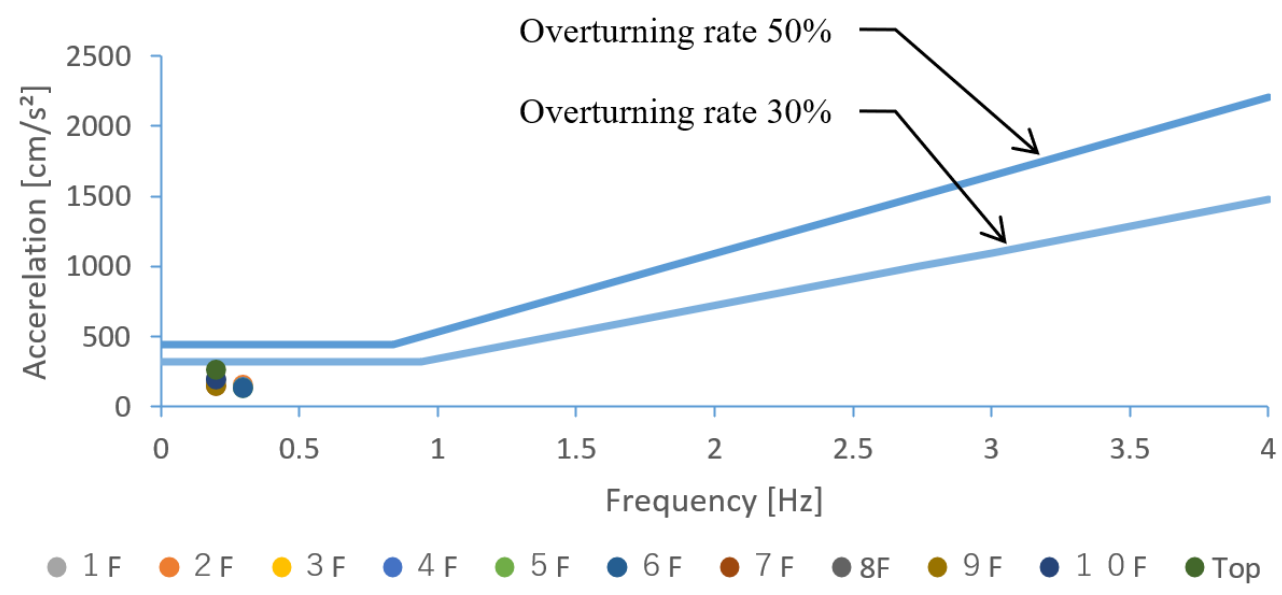

Figure 11: Acceleration and floor response for the isolated 10-storey building (no collision).

To study collision cases, for the 5-storey building the results corresponding to the input motion with an amplification factor of 1.8 were selected and for the 10-storey building the results of the input motion with an amplification factor of 2 were chosen. In these both cases the maximum displacements are similar $(48.9 \mathrm{~cm}$ for the 5 -storey building and $48.6 \mathrm{~cm}$ for the 10-storey building) and the collision produces higher accelerations.

Fig. 12 shows the safety analysis of the 5-storey building in the event of a collision. Only the first floor is below the $50 \%$ overturning probability curve. The rest of the floors exceed the $50 \%$ probability of overturning.

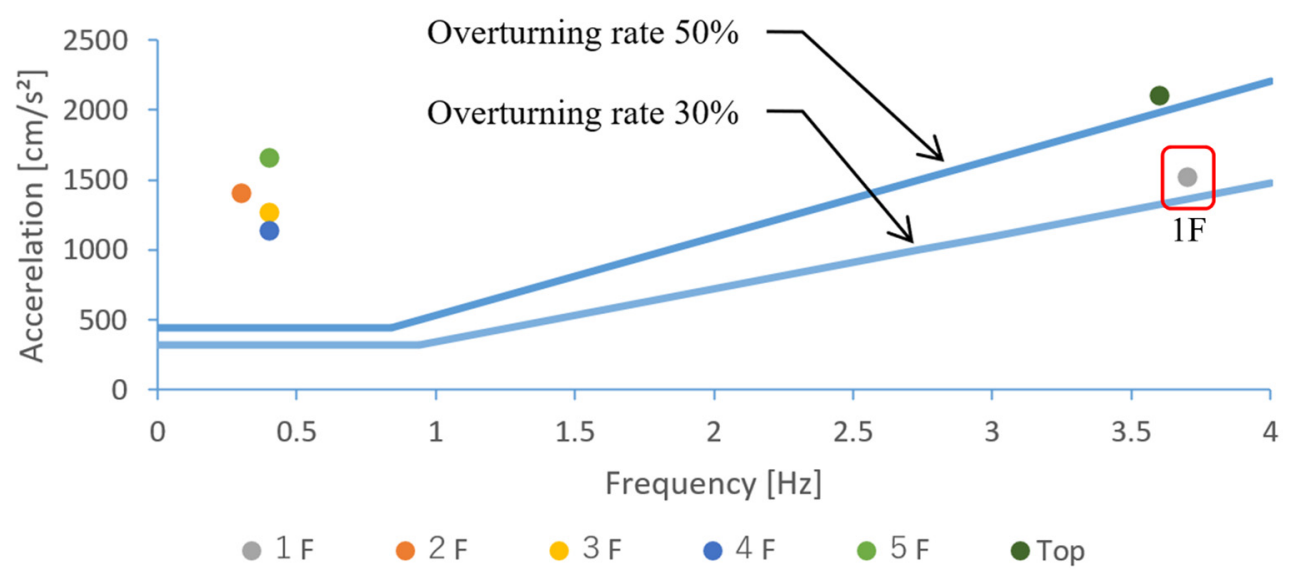

Figure 12: Safety analysis of the isolated 5-storey building in case of collision. 
Fig. 13 shows the safety analysis of the 10-storey building in the event of a collision. In this case, the acceleration of the first floor, the second floor and the third floor are below the $50 \%$ overturning probability curve. The rest of floors exceed the $50 \%$ probability of overturning.

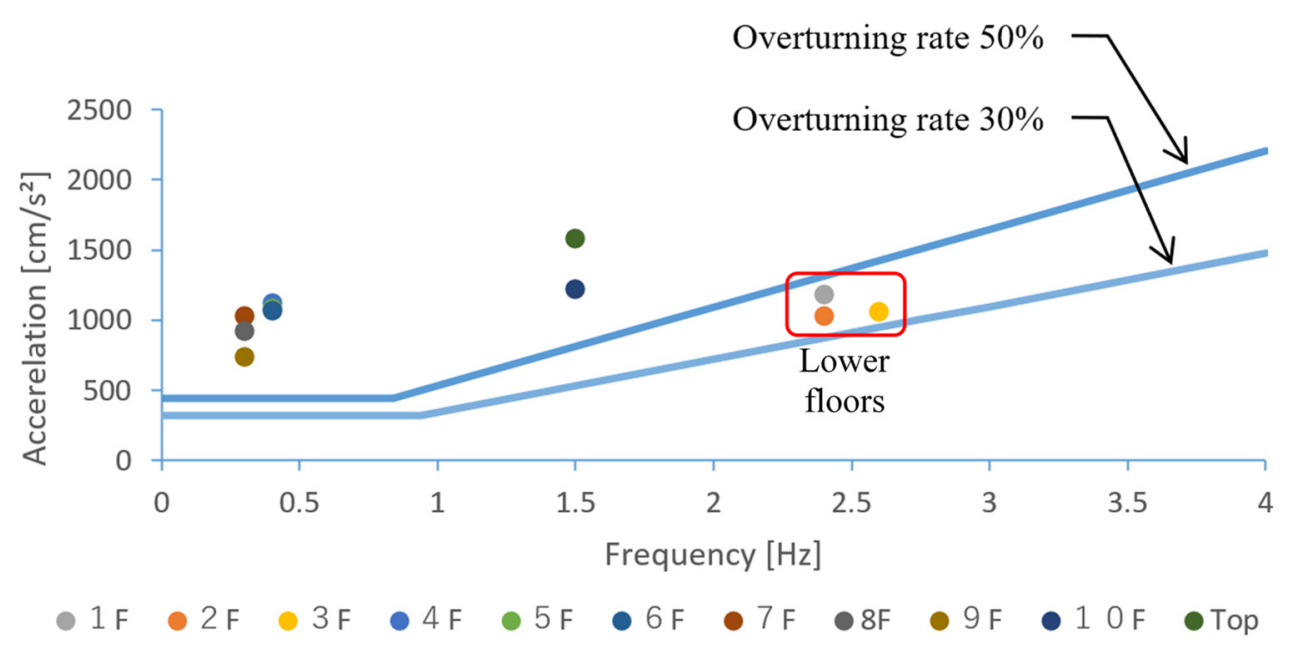

Figure 13: Safety analysis of the isolated 10-storey building in case of collision.

\section{CONCLUSIONS}

The 5-storey and 10-storey base-isolated buildings selected in this study have similar periods of vibration. However, the collision was confirmed in the first building when the Kobe seismic wave was amplified 1.7 times, and in the second building an amplification factor of 1.8 was required to produce the collision.

It was found that the behaviour of the isolated building at the time of collision with the retaining wall is greatly affected by the amount of displacement in which the response displacement exceeds the clearance.

If the isolated building does not collide with the retaining wall, the probability of the interior furniture will fall is less than $30 \%$.

In cases of collision with the retaining wall, the probability of furniture overturning is greater than $50 \%$ in most floors. The equivalent frequency of the floor response tends to increase near the first floor and the vicinity of the upper floor, reducing the probability of overturning on these floors. It was also observed that the probability of furniture overturning is higher on the upper floors compared to the lower floor.

\section{REFERENCES}

[1] Hatada, K. \& Cuadra, C., Dynamic response of low-rise building with different base isolation devices. Proceedings of the 15th European Conference on Earthquake Engineering, Istanbul, Turkey, Paper No.397, 2014.

[2] The Japan Society of Seismic Isolation, Data on the number of seismic isolated buildings and vibration controlled buildings, 2019. (In Japanese.) https://www.jssi.or.jp/menshin/ doc/ms_ss_data.pdf. 
[3] Cuadra, C. \& Meguro, J., Evaluation of the dynamic characteristics of a base-isolated low-rise RC building after the Great East Japan Earthquake. Proceedings of the 15th World Conference on Earthquake Engineering, 24-28 September, Lisbon, Portugal, Paper No. 1284, 2012.

[4] Miwada, G., Komaki, J., Sato, K., Sano, T., Katsumata, H., Takiyama, N. \& Hayashi, Y., Experiments and simulation analysis of collision to retaining wall with real scale base-isolated building. The Architectural Institute of Japan's Journal of Structural and Construction Engineering, 76(663), 2011. (In Japanese.)

[5] Miwada, G., Sano, T. \& Katsumata, H., Experiments of collision to retaining wall with real-scale base-isolated building. Research Institute of Technology, Obayashi Corporation, Report No.74, 2010. (In Japanese.)

[6] Sasaki, T., Sato, E., Fukuyama, K. \& Kajiwara, K., Enhancement of base-isolation based on e-defense full scale shake table experiments: Dynamic response of base-isolated building under impact due to pounding. Proceedings of the 16th World Conference on Earthquake, 16WCEE 2017, Santiago Chile, 9-13 January, Paper No. 4082, 2017.

[7] Nakamura, S., Suzuki, T., Tojo, T., Asahara, S., Kinoshita, T. \& Nakamura, N., Analytical study of the evaluation procedure and effect when base-isolated building collides with retaining wall. Proceedings of the 16th World Conference on Earthquake, 16WCEE 2017, Santiago Chile, 9-13 January, Paper No. 1467, 2017.

[8] Cuadra, C. \& Hasegawa, J., Safety of base-isolated building in case of impact against retaining wall. International Journal of Safety and Security Engineering, 9(3), pp. 269279, 2019.

[9] Kaneko, M., Nakamura, Y., Kambara, H. \& Tamura, K., Seismic safety evaluation method for building contents. Proceedings of the 14th World Conference on Earthquake Engineering, 12-17 October, Beijing, China, Paper No. 14_S20-002, 2008. 